\title{
A Test for the Cobb Douglas Production Function in Manufacturing Sector: The Case of Bangladesh
}

\author{
Shaiara Husain*, Md. Shahidul Islam \\ Department of Economics, Southeast University, Dhaka, Bangladesh
}

Email address:

shuma153@yahoo.com (S. Husain)

${ }^{*}$ Corresponding author

\section{To cite this article:}

Shaiara Husain, Md. Shahidul Islam. A Test for the Cobb Douglas Production Function in Manufacturing Sector: The Case of Bangladesh. International Journal of Business and Economics Research. Vol. 5, No. 5, 2016, pp. 149-154. doi: 10.11648/j.ijber.20160505.13

Received: August 16, 2016; Accepted: September 1, 2016; Published: September 21, 2016

\begin{abstract}
The manufacturing sector has been a major driver of GDP growth in Bangladesh. The sector recorded an impressive average annual growth during last a couple of decades. This study is an attempt to test empirically the CobbDouglas production function for manufacturing sector of Bangladesh. Data of total value of output, total asset, total liabilities, number of permanent workers etc. of about six major types of industries including Garments, Textiles, Food \& Food Processing, Leather \& Leather Products, Electronics and Chemicals \& Pharmaceuticals have been used. Researchers use total value of output as $\mathrm{Y}$, total liabilities as $\mathrm{K}$, and number of permanent workers (including officials managers, personal) as L. Study finds that coefficient for $\mathrm{K}$ and $\mathrm{L}$ are 0.49 and 0.51 respectively for entire manufacturing sector. In case of Garments, coefficient for $\mathrm{K}$ is 0.30 and $\mathrm{L}$ is 0.61 implying that labor is more productive than capital. The statement is also true for Textile sector and Leather \& leather products. Capital is, on other hand, more productive than labor in Food \& food processing industries, Electronics, Chemicals \& Pharmaceuticals sectors. The coefficients are significant and do not suffer from MC and also not from Autocorrelation. To correct heteroscedasticity, WLS method (weighted Least Square) has been adopted. Findings reveal that Cobb-Douglas production function is applicable and exhibits increasing returns to scale in the context of manufacturing sector of Bangladesh.
\end{abstract}

Keywords: Manufacturing Sector, Cobb-Douglas Production Function, Productivity, Labor, Capital

\section{Introduction}

Given the ambitious growth targets of the vision 2021 of Bangladesh, it is considered very important to give serious attention to the manufacturing sector for employment expansion, productivity enhancement and increasing per capita income oriented to reduction of poverty in the country. The sector recorded an impressive average annual growth during a last couple of decades. Given the still modest share in GDP, manufacturing sector has considerable scope to lead the growth process.

Production function provides quantitative link between inputs and outputs. Economists prefer to use the CobbDouglas functional form $Y=f(K, L)=A K^{\alpha} L^{\beta}$, where $Y$ is the output, $\mathrm{K}$ is the capital, and $\mathrm{L}$ is the labor, $\alpha+\beta=1 \quad \alpha, \beta \geq 0$ $\mathrm{K}, \mathrm{L}>0$ because it provides a relatively accurate description of the economy and is very easy to work with algebraically.
The popularity of this function is due to the fact, it is amenable to easy mathematical manipulations and it satisfies the restrictions imposed on production function. These restrictions are: (1) both inputs are essential for production such that no output can be produced without using at least some of both inputs; (2) The marginal product of each input is positive; (3) the marginal product diminishes with increased use of each of the inputs; (4) The marginal product of an input increases with increased use of the other input.

Because of above logical and consistent characteristics, Cobb-Douglas production function has been considered to be tested in manufacturing sector of Bangladesh. There does not appear to be overwhelming evidence that would lead one to choose the CES over the Cobb-Douglas for forecasting GDP and income shares. When empirical estimates are restricted to the Cobb-Douglas form, the fit tends to be quite good [1].

Recently, businessmen as well as industrialists are very much concerned about the theory of firm in order to make 
correct decisions regarding what items, how much and how to produce them. All these decisions are directly related with the cost considerations and market situations where the firm is to be operated. In this regard, this paper should be helpful in suggesting the most suitable functional form of production process for the major manufacturing industries of developing countries like Bangladesh. This study is an attempt to test empirically the Cobb-Douglas production function for manufacturing sector of Bangladesh with the validity of all its assumptions.

\section{Review of Literature}

[2] considered the manufacturing sector of south-west region of Bangladesh and apply Cobb-Douglas production to estimate the productivity, allocative efficiency and measuring returns to scale. The study showed cement, jute, and textile manufacturing firms having decreasing returns to scale whereas fertilizers and seafood processing firms have increasing returns to scale. The estimated value of marginal productivity and allocative efficiency revealed that labor productivity of all sorts of manufacturing firms is greater than that of capital productivity. Therefore, additional employment can be generated by utilizing labor intensive technique. If investors invest in labor intensive technique, they can expect a positive return from investment. Regression analysis and hypothesis testing of the study show that labor input has a significant impact on the production of these manufacturing firms. The estimation of Cobb- Douglas production function which showed that labor and capital inputs influence the total variation of production of cement, fertilizer, jute, sea foods and textile firms respectively $0.927 \%, 0.917 \%, 0.90 \%, 0.928 \%$ and $0.851 \%$ respectively. The study also used marginal productivity of labor and capital by taking partial derivation of Cobb-Douglas production function which shows that the marginal productivity of labor of these firms is greater than that of capital. Therefore, these firms could reduce production cost by shifting resources from capital intensive technique to labor intensive technique and at the same time they can generate additional employment opportunities.

[3] shows that Cobb-Douglas Production function is the only production function which has the property of a constant functional distribution of income of the factors of production. The estimation of the parameters of an aggregate production function is central in work on growth and productivity.

[4] estimates Cobb-Douglas Production function and detects that industries in Bangladesh have potential allocative efficiency as they are using at least some capital. By estimating the marginal productivity of labor and capital, study explains that allocative efficiency is achievable through appropriate pricing of capital and its proper disbursement among the proprietorships.

[5] deals with the issue of improving economic efficiency in sawn wood in Ondo and Osun states, southwest Nigeria. The stochastic frontier approach is used to estimate a self dual Cobb-Douglas production function which gives estimates of technical, allocative and economic efficiencies. The study shows that, on average, sawmills in Ondo and Osun states have high technical, allocative and economic efficiencies. In both states, sawmills have the potential to either increase output using the same level of input or to reduce the present level of input use for the same level of output.

[6] investigates the technical efficiency of selected manufacturing industries of Bangladesh using a stochastic frontier production function approach. A feasible CobbDouglas stochastic frontier production function, which has time-varying technical inefficiency effects, is estimated. In the study, researchers have analyzed the stochastic frontier production function using panel data in selected manufacturing industries in Bangladesh. Two alternative distributions are used to model the random inefficiency term: a truncated normal distribution and a half-normal distribution. Researchers have observed that the estimated values of the time-varying inefficiency parameter are positive for both the truncated and the half normal distribution. These indicate that technical inefficiency has declined over the reference period. Tests for different null hypotheses involved in the stochastic frontier production function show that the technical inefficiency effects for the selected manufacturing industries in Bangladesh are significant. It has been found that the mean efficiencies according to the truncated and the half normal distributions are 0.4022 and 0.5557 respectively. Here it should be noted that although the growth in technical efficiency is statistically significant over time as tested by the null hypothesis, the rate of increase in technical efficiency has been very slow over time in Bangladesh.

[7] noticed increasing concern of businessmen as well as industrialists about the theory of firm in order to make correct decisions regarding what items, how much and how to produce them. Researchers wanted to suggest the most suitable functional form of production process for the major manufacturing industries in Bangladesh. The study considers Cobb-Douglas (C-D) production function with additive error and multiplicative error term. The main purpose of the study is to select the appropriate Cobb-Douglas production model for measuring the production process of some selected manufacturing industries in Bangladesh. Researchers use different model selection criteria to compare the CobbDouglas production function with additive error term to Cobb-Douglas production function with multiplicative error term.

[8] derived the exact distribution of the indirect least square estimators of the coefficients of the Cobb-Douglas production function. Researcher developed a model in which a Cobb- Douglas type function is coupled with simultaneous multiplicative and additive errors. The specification was a natural generalization of the "pure" models in which either additive or multiplicative stochastic terms were introduced. Researcher used a maximum likelihood approach to the estimation of a Cobb-Douglas type model when the model included both multiplicative and additive disturbance terms. Because of the complexity of the likelihood function, 
maximization algorithm had been used.

[9] estimated production functions for Indian manufacturing industries and to find whether plausible and meaningful estimates can be obtained for returns to scale, substitution, distribution, and efficiency parameters. Data had been collected through surveys specially designed for estimating the levels of technical efficiency (TE) and variations in $\mathrm{TE}$ only in small-scale industrial units. Researchers found little variation in TEs across industry groups and a high level of average TE in each industry groups.

[10] found that, the Cobb-Douglas production function with additive error performs better for the selected manufacturing industries based on the data under study period. Thus the strictly nonlinear models (which are nonlinear with additive error terms) seemed to be better than intrinsically linear model (which are nonlinear with multiplicative error terms). Researchers estimated the parameters of the Cobb-Douglas production function with additive errors by using optimization subroutine. The estimates showed economies of scale in the manufacturing of drugs \& pharmaceuticals, Furniture \& fixtures, Iron \& steel basic, Leather footwear, Fabricated metal products, Plastic products, Printing \& publications and Tobacco. There are diseconomies of scale in the Beverage, Chemical, Glass \& glass products, Leather \& leather products, Paper \& paper products, Textile, Wood \& crock products industries and Transport equipment.

\section{Methodology and Data}

In this study, data are collected from Bangladesh Bureau of Statistics (Survey of manufacturing industries 2012) and World Bank on various types of industries depending on their performance, employment size, disturbance due to various national and international affairs, inputs, imports, exports, nature of ownership (pvt or plc or state owned) etc. for the year 2012. From a total number of 1003 firms including Garments, Textiles, Food \& Food Processing, Leather \& Leather Products, Electronics, Chemicals \& Pharmaceuticals; 979 samples are collected. For the Exporter Industries, sample size is 467 and for the non exporter industries, sample size is 512. Data on about six major type of industries are available. Information about exporter industries (among these) and non exporter industries are also available.

The study uses total value of output as Y, total liabilities as $\mathrm{K}$, and number of permanent worker (including officials, managers, personal) as L.

The Cobb-Douglas Production Function:

The Cobb-Douglas Production, in its stochastic form, may be expressed as

$$
\mathrm{Y}=\mathrm{f}(\mathrm{K}, \mathrm{L})=A K^{\alpha} \mathrm{L}^{\beta} \mathrm{e}^{\mathrm{U}}
$$

Where, $\mathrm{Y}=$ Output, $\mathrm{K}=$ capital, $\mathrm{L}=\mathrm{Labor}, \mathrm{U}=$ Stochastic disturbance term, $\mathrm{e}=$ Base of natural logarithm.

From this equation it is clear that the relationship between output and the two inputs is nonlinear. However, log transformation of this model is as follows:

$$
\begin{gathered}
\operatorname{LnY}=\operatorname{Ln} A+\alpha \operatorname{Ln} \mathrm{K}+\beta \operatorname{LnL}+\mathrm{u}_{\mathrm{i}} \mathrm{L} \\
=\mathrm{B}+\alpha \operatorname{Ln} \mathrm{K}+\beta \operatorname{LnL}+\mathrm{u}_{\mathrm{i}}, \text { where } \mathrm{B}=\operatorname{Ln} \mathrm{A}
\end{gathered}
$$

Thus written, the model is linear in the parameters $B, \alpha$ and $\beta$ and is therefore a linear regression model. It may be mentioned here that though it is nonlinear in the variables $\mathrm{Y}$ and $\mathrm{K}, \mathrm{L}$ but linear in the logs of these variables. In short, equation (3) is a $\log \log$, double $\log$, or log linear model.

The empirical analysis has been carried out to study $\alpha$, the (partial) elasticity of output with respect to the capital input, and $\beta$, the partial elasticity with respect to labor for the whole industries.

In this part, informationwill be examined in regression of whole industry about the possibility of violation of CLRM assumption, ie Multicollinearity (MC) Autocorrelation, \& Heteroscedasticty.

It is expected that the result will not be affected by MC. Though it is a matter of suspicion that as the study is about Cobb-Douglas production function, there might exist a linear relationship between two inputs, such as in a garments factory a women worker may operate only one sewing machine. In this regard, MC might be a simple phenomenon. As the study has a large sample size consist of different type of industries and some of them are labor intensive (ex: garments) and some are capital intensive (Ex: Electronics, Chemical \& Pharmaceutical), linear relationship in regression of whole industrial sector is expected to be prevented and degree of collinearity is expected to be reduced.

It is also expected that the original equation is not affected by Autocorrelation. Actually there is no reason to believe that disturbance term of a garments industry can be affected by disturbance of a leather industry or electronics industry because the data are cross sectional. It has been reconfirmed by checking DW statistic.

But it's thought that heteroscedastictiy might exist in present case as there is a big heterogeneity in samples. Since the data contain information about six broad categories of industries and some of these are exporters, production may be affected by national and international event. To be clear, BPG test and White test have been done due to their suitability.

Finally it has been tried to remove heteroscedasticityby applying WLS. Weight $\left(1 / \sigma_{\mathrm{i}}\right)$ has been derived by calculating $\sigma_{\mathrm{i}}$ of different industries (for every type separately) and also for Exporter industries \& Non exporter industries separately. The following regression has been run:

$$
(\operatorname{Ln~Y}) / \sigma_{\mathrm{i}}=\mathrm{B} / \sigma_{\mathrm{i}}+\alpha\left\{(\mathrm{LnK}) / \sigma_{\mathrm{i}}\right\}+\beta\left\{(\mathrm{LnL}) / \sigma_{\mathrm{i}}\right\}+\mathrm{u}_{\mathrm{i}} / \sigma_{\mathrm{i}}
$$

The hypothesis of constant returns to scale (CRS) using Restricted Least Square Model (RLS) and F test have also been examined.

\section{Findings}

The following regression equationsare obtained for the 
whole Industrial Sector of Bangladesh. $(\mathrm{N}=979)$ :

Table 1. Whole Industrial Sector of Bangladesh.

\begin{tabular}{lccc}
\hline se & $(0.164)$ & $(0.019)$ & $(0.025)$ \\
$\mathrm{t}$ & $(20.67)$ & $(25.31)$ & $(19.88)$ \\
$\mathrm{R}^{2}=0.714, \mathrm{DW}=1.78, \mathrm{VIF}=1.501$, & $\mathrm{TOL}=.666, \mathrm{~F}=1216.110$ \\
\hline
\end{tabular}

$$
\mathrm{LnY}=3.381+0.489 \mathrm{Lnk}+0.505 \mathrm{LnL}+\mathrm{U}_{\mathrm{i}}
$$

For the Garments Industry $(\mathrm{N}=304)$ the equation is,

Table 2. Garments Industry

\begin{tabular}{lccc}
\hline se & $(0.398)$ & $(0.040)$ & $(0.057)$ \\
$\mathrm{t}$ & $(11.95)$ & $(7.608)$ & $(10.661)$ \\
$\mathrm{R}^{2}=0.492, \mathrm{DW}=1.904, \mathrm{VIF}=1.216$, & $\mathrm{TOL}=.823, \mathrm{~F}=145.810$ \\
\hline
\end{tabular}

$$
\mathrm{LnY}=4.756+0.301 \mathrm{Lnk}+0.609 \mathrm{LnL}+\mathrm{U}_{\mathrm{i}}
$$

For the Textiles $(\mathrm{N}=253)$ the equation is,

Table 3. Textile Industry.

\begin{tabular}{lccc}
\hline se & $(0.313)$ & $(0.041)$ & $(0.062)$ \\
$\mathrm{t}$ & $(9.423)$ & $(10.061)$ & $(11.481)$ \\
$\mathrm{R}^{2}=0.77, \mathrm{DW}=1.66, \mathrm{VIF}=2.061$, & $\mathrm{TOL}=.485, \mathrm{~F}=411.038$ \\
\hline
\end{tabular}

$$
\mathrm{LnY}=2.954+0.409 \mathrm{Lnk}+0.712 \mathrm{LnL}+\mathrm{U}_{\mathrm{i}}
$$

For the Food \& Food Processing industries $(\mathrm{N}=143)$ the equation is,

Table 4. Food \& Food Processing Industry.

\begin{tabular}{llll}
\hline $\mathrm{se}$ & $(.436)$ & $(.059)$ & $(.083)$ \\
$\mathrm{t}$ & $(6.511)$ & $(11.877)$ & $(2.256)$ \\
$\mathrm{R}^{2}=0.68, \mathrm{DW}=1.8, \mathrm{VIF}=1.656, \mathrm{TOL}=.604, \mathrm{~F}=148.938$ \\
\hline
\end{tabular}

$$
\mathrm{LnY}=2.838+0.696 \mathrm{Lnk}+0.188 \mathrm{LnL}+\mathrm{U}_{\mathrm{i}}
$$

For the Leather \& Leather Products (Sample size $=\mathrm{N}=95$ ) the equation is,

Table 5. Leather \& Leather Products Industry.

\begin{tabular}{lccc}
\hline $\mathrm{se}$ & $(.694)$ & $(.074)$ & $(.117)$ \\
$\mathrm{t}$ & $(6.128)$ & $(5.653)$ & $(4.419)$ \\
$\mathrm{R}^{2}=0.54, \mathrm{DW}=1.9, \mathrm{VIF}=1.372, \mathrm{TOL}=.729, \mathrm{~F}=53.158$ \\
\hline
\end{tabular}

$$
\mathrm{LnY}=4.253+0.418 \mathrm{Lnk}+0.517 \mathrm{LnL}+\mathrm{U}_{\mathrm{i}}
$$

For the Electronics $(\mathrm{N}=91)$ the equation is,

Table 6. Electronic Industry.

\begin{tabular}{lccl}
\hline se & $(.426)$ & $(.065)$ & $(.093)$ \\
$\mathrm{t}$ & $(6.478)$ & $(9.33)$ & $(4.176)$ \\
$\mathrm{R}^{2}=0.787, \mathrm{DW}=2.24, \mathrm{VIF}=2.031$, & $\mathrm{TOL}=0.498, \mathrm{~F}=162.542$ \\
\hline
\end{tabular}

$$
\mathrm{LnY}=2.761+0.609 \mathrm{Lnk}+0.389 \mathrm{LnL}+\mathrm{U}_{\mathrm{i}}
$$

For the Chemicals \& Pharmaceuticals $(\mathrm{N}=82)$ the equation is,
Table 7. Chemicals \& Pharmaceuticals Industry.

\begin{tabular}{llll}
\hline se & $(.506)$ & $(.066)$ & $(.100)$ \\
$\mathrm{t}$ & $(3.392)$ & $(9.096)$ & $(5.721)$ \\
$\mathrm{R}^{2}=0.828, \mathrm{DW}=1.812, \mathrm{VIF}=2.015, \mathrm{TOL}=0.496, \mathrm{~F}=190.797$ & \\
\hline & $\mathrm{LnY}=1.716+0.597 \mathrm{Lnk}+0.573 \mathrm{LnL}+\mathrm{U}_{\mathrm{i}}$
\end{tabular}

For the Exporter Industries $(\mathrm{N}=467)$ the equation is,

Table 8. Exporter Industry.

\begin{tabular}{llll}
\hline SE & $(0.304)$ & $(0.026)$ & $(0.036)$ \\
$\mathrm{T}$ & $(12.951)$ & $(17.892)$ & $(12.783)$ \\
$\mathrm{R}^{2}=0.566, \mathrm{DW}=1.64, \mathrm{VIF}=1.046, \mathrm{TOL}=.956, \mathrm{~F}=303.066$
\end{tabular}

For the Non Exporter Industries $(\mathrm{N}=502)$ the equation is,

Table 9. Non-exporter Industry.

\begin{tabular}{lccc}
\hline se & $(.216)$ & $(.031)$ & $(.045)$ \\
$\mathrm{t}$ & $(14.993)$ & $(16.498)$ & $(10.083)$ \\
$\mathrm{R}^{2}=0.734, \mathrm{DW}=1.70, \mathrm{VIF}=2.223, \mathrm{TOL}=0.45, \mathrm{~F}=689.382$
\end{tabular}

On the basis of above information it may be said that, the coefficients are significant and do not suffer from multicollinearity, at least do not from perfect multicollinearity, which is evident from the value of VIF \& TOL and also free from the problem of autocorrelation as the values of DW statistic near about 2, and the study is dealing with cross section data. However, it was suspected that the original equation would demonstrate regression heterogeneityin type of industries. So information (residuals) have been tested formally and; BPG (Breusch-PaganGodfrey) test and White's General' Heteroscedastictiy test have been followed.

Through BPG test, it is seen that observed $\Theta$ (ESS1/2) which follows $\chi^{2} \mathrm{~m}-1$ distribution is 24.612 which is significant at both $5 \%$ \& $1 \%$ level of significance. So, null hypothesis of homoscedasticity can easily be rejected.

Through White test, it is observed that the value of $\mathrm{n} \mathrm{R}^{2}$ (which asymptotically approaches to $\chi^{2} \mathrm{df}$ ) is 71.467 .

The $5 \%$ critical value for $5 \mathrm{df}$ is 11.075 , the $10 \%$ critical value is 9.2363 and the $25 \%$ critical value is 6.62568 . It can be said on the basis of these information that there is heteroscedasticity.

To correct heteroscedasticity, WLS (weighted Least Square) methodhas been followed. At first stage, the outcome has been derived according to the assumption of heteroscedasticity which may be a result of heterogeneity (due to types) of industries. Then the new result (weighted) is as follows.

Table 10. Whole Industry sector of Bangladesh (Corrected for Heteroscedasticity).

\begin{tabular}{lllll}
\hline & $\mathrm{se}$ & $(.193)$ & $(.0253)$ & $(.031)$ \\
& $\mathrm{t}$ & $(12.854)$ & $(24.312)$ & $(22.007)$ \\
$\mathrm{R}^{2}=0.848$ & $\mathrm{DW}=1.54$ & $\mathrm{VIF}=2.810$ & $\mathrm{TOL}=0.356$ & \\
\hline
\end{tabular}


$(\operatorname{Ln~Y}) / \sigma_{\mathrm{i}}=2.476\left(1 / \sigma_{\mathrm{i}}\right)+.553\left\{(\mathrm{LnK}) / \sigma_{\mathrm{i}}\right\}+.680\left\{(\mathrm{LnL}) / \sigma_{\mathrm{i}}\right\}(14)$

In second Stage, now the study is interested to derive corrected result according to the assumption of heterogeneity (due to exporter or non exporter).

Table 11. Exporter or Non-exporter Industry (Corrected for Heteroscedasticity).

\begin{tabular}{lllll}
\hline & $\mathrm{se}$ & $(.172)$ & $(.020)$ & $(.027)$ \\
& $\mathrm{t}$ & $(14.854)$ & $(28.430)$ & $(22.898)$ \\
$\mathrm{R}^{2}=0.848$ & $\mathrm{DW}=1.5$ & $\mathrm{VIF}=2.008$ & $\mathrm{TOL}=0.479$ & \\
\hline
\end{tabular}

$(\operatorname{Ln~Y}) / \sigma_{i}=2.556\left(1 / \sigma_{i}\right)+0.562\left\{(\operatorname{LnK}) / \sigma_{i}\right\}+0.607\left\{(\operatorname{LnL}) / \sigma_{i}\right\}$

All of the above parameters and coefficients are highly significant. The results now show that the industrial sector is characterized by increasing returns to scale. On this circumstance, the study is now eager to test a hypothesis (null) of constant returns to scale (CRS) through restricted least square (RLS) especially by F testing,

$$
\left.\left.\mathrm{F}=\left\{\mathrm{RSS}_{\mathrm{R}}-\mathrm{RSS}_{\mathrm{UR}}\right) / \mathrm{m}\right\} /\left\{\mathrm{RSS}_{\mathrm{UR}} / \mathrm{n}-\mathrm{k}\right)\right\}
$$

$$
=(2074.3-1785.53) /(1785.53 / 976)=288.77 / 1.83=157.8
$$

Where $\mathrm{RSS}_{\mathrm{R}}=$ residual sum of square of restricted model, RSSUR is the residual sum of square of unrestricted model, $\mathrm{m}=$ number of restriction ( 1 in the present study), $\mathrm{n}=$ number of observations, $\mathrm{k}=$ number of parameter. The $\mathrm{F}$ value follows the $\mathrm{F}$ distribution with $1 \mathrm{df}$ in the numerator and 976df in the denominator, which is clearly significant and the null hypothesis of CRS can be rejected. So,It can be said that the industrial sector (as a whole) probably characterized by IRS (increasing returns to scale) and using mere RLS may not give proper information.

\section{Economic Interpretation \& Limitation}

Assuming total value ofoutput as $\mathrm{Y}$, total liabilities as $\mathrm{K}$, and number of permanent workers (including official managers, personal)as L, analysis finds that coefficient for capital $(\mathrm{K})$ is 0.49 and coefficient for labor $(\mathrm{L})$ is 0.51 for entire manufacturing sector. It means that in manufacturing sector, if amount of capital increases by 1 unit, production increases by 0.49 unit remaining other variables constant; and if amount of labor employment increases by 1 unit, production increases by 0.51 unit remaining other variables constant. It reveals that labor is more productive than capital in manufacturing sector of Bangladesh.

In case of Garments, coefficient for $\mathrm{K}$ is 0.30 and $\mathrm{L}$ is 0.61 . It shows productivity of inputs that labor is more productive than capital. The statement is also true for Textile sector and Leather \& leather products. Capital is, on other hand, more productive than labor in Food \& food processing industries, Electronics, Chemicals \& pharmaceuticals sectors. In Electronics sector, coefficient for $\mathrm{K}$ is 0.61 and $\mathrm{L}$ is 0.39 . It means that in Electronics sector, if amount of capital increases by 1 unit, production increases by 0.61 unit remaining other variables constant; and if amount of labor employment increases by 1 unit, production increases by 0.39 unit remaining other variables constant. It reveals that capital is more productive than labor in Electronics sector of Bangladesh.

The findings indicate that labor should be employed more in Garments sector, Textile sector and Leather \& leather products in order to increase production (economic growth) as well as economic development. On the other hand, capital should be employed more in Food \& food processing industries, Electronics, Chemicals \& pharmaceuticals sectors.

This paper is based on the data set from the survey of manufacturing sector 2012 where the data is being updated up to 2012 and six major types of industries are being taken into account. More recent data up to 2015 and including other major types of industries in the calculation can be an avenue for future research in this area.

\section{Conclusion}

From the findings of this study, it can be said that CobbDouglas production function is applicable in the context of manufacturing sector of Bangladesh and revealing an interesting aspect that this sector exhibits increasing returns to scale. It means that increase in production is more than increase in employment of inputs (capital, labor) in production process which is very much optimistic result for future investment decisions both form the government and private sector which might be helpful for employment generation and for also potential economic development.

\section{References}

[1] Miller, E. (2008) 'An Assessment of CES and Cobb-Douglas Production Functions', Congressional Budget Office.

Retrieved

from:https:/www.cbo.gov/sites/default/files/cbofiles/ftpdocs/9 4xx/doc9497/2008-05.pdf

[2] Hossain, M. S. \& Islam, A. N. (2013) 'Productivity Analysis and Measuring the Returns to Scale of Manufacturing Firms in the South-West Region of Bangladesh', IOSR Journal Of Humanities And Social Science (IOSR-JHSS),vol.17, no.1, pp. 69-77.

[3] Hagendorf, K. (2009) 'The Cobb-Douglas Production Function and Political Economy', Journal of Political Economy, vol.69, no.8, pp. 69-79.

[4] Hossain, S. I. (1987) Allocative and Technical Efficiency: 'A Study of Rural Enterprises in Bangladesh', The Journal of Developing Economics, vol.25, no.1, pp. 56-72.

[5] Kehindi, A. L. \& T. T. Awoyem. (2009) 'Analysis of Economics Efficiency in Sawn wood Production in Southwest Nigeria', Journal of Human Ecology, vol.26, no.3, pp. 175183.

[6] Baten, M. A., Rana, M. Das, S. \&Khaleque, M. A. (2006) 'Technical Efficiency of Some Selected Manufacturing Industries in Bangladesh: A Stochastic Frontier Analysis',The Lahore Journal of Economics, vol.11, no 2, pp 23-41. 
[7] Hossain, M. M., Majumder, A. K. \&Basak, T. (2012) 'An Application of Non-Linear Cobb-Douglas Production Function to Selected Manufacturing Industries in Bangladesh', Open Journal of Statistics, vol. 2, pp. 460-468.

[8] Wu, D. M. (1975) 'Estimation of the Cobb-Douglas Production Function', Econometrica, vol. 43, no.4, pp. 739744.
[9] Bhashin, V. K. \& Seth, V. K. (1980) 'Estimation of production Functions for Indian Manufacturing Industries', Indian Journal of Industrial Relations, vol.15, no.3, pp. 395-409.

[10] Hossain, M. Z., Bhatti, M. I. \& Ali, M. Z. (2004) 'An Econometric Analysis of Some Major Manufacturing Industries: A Case Study',Managerial Auditing Journal, vol.19, no.6, pp. 790-795. 